2. Bennett AN, McGonagle D, O'Connor P, Hensor EM, Sivera F, Coates LC, et al. Arthritis Rheum. 2008;58:3413-8.

3. Sieper J, Srinivasan S, Zamani O, Mielants H, Choquette D, Pavelka K, et al. Ann Rheum Dis. 2013;72:1621-7.

4. Lehr J, Rahman P, O'Rielly DD. J Rheumatol. 2017 Jun;44(6):962-963.

Disclosure of Interest: None declared

DOI: 10.1136/annrheumdis-2018-eular.6787

\section{FRI0635 MEDICATION ADHERENCE IN PATIENTS WITH RHEUMATIC DISEASES: A QUALITATIVE STUDY IN A BIOLOGICS CLINIC}

S. Raghunath ${ }^{1,2,}$, R. Hijjawi ${ }^{3}$, E. Hoon ${ }^{4}$, E. M. Shanahan ${ }^{2,3}$, F. Goldblatt ${ }^{2,3}$ ${ }^{1}$ Monash Health, Melbourne, ${ }^{2}$ Southern Adelaide Local Health Network, ${ }^{3}$ Flinders University, ${ }^{4}$ University of Adelaide, Adelaide, Australia

Background: High rates of non-adherence to prescribed medications in rheumatic diseases have been reported, with adherence as low as 30\% in some studies [1, 2]. Physicians commonly overestimate adherence [3]. Consequences of non-adherence include poorer patient outcomes and increased healthcare costs $[1,2]$. Improving adherence may be as effective as developments in biomedical management in terms of positive health outcomes [4]. Understanding factors contributing to non-adherence may inform strategies for improvement.

Objectives: This study aims to explore factors affecting medication adherence in patients attending a dedicated biologics clinic.

Methods: Patients were selected by purposive sampling. Semi-structured interviews were performed and continued until data saturation was achieved in order to examine reasons why patients failed to take their prescribed medication. Interviews were transcribed and coded using NVIVO. The principles of grounded theory were used to analyse the data. The emergent themes were informed by health behaviour theories and factors which have previously correlated with adherence in similar cohorts.

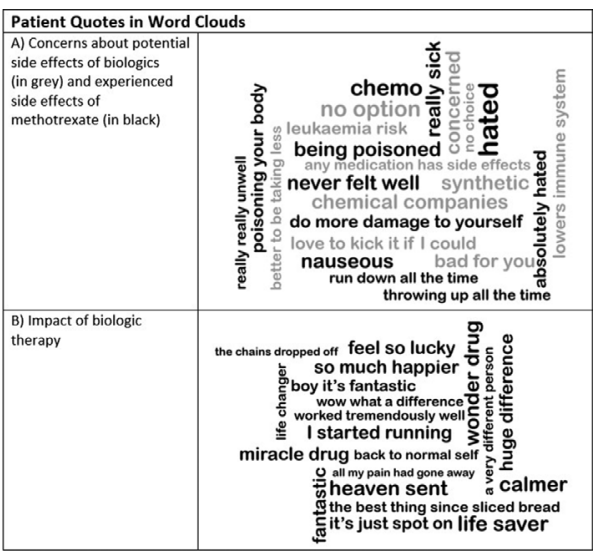

Results: Major themes which emerged include the concept that the presence of active symptoms significantly influenced adherence. It was noted that patients tended not to prioritise medication taking until they had recurrence of symptoms. Patients sometimes failed to display an understanding of the concept of disease activity, or concern for the risk of long term joint damage or other consequences of uncontrolled inflammation. They also expressed concern regarding potential longterm side effects of biologic medications; even if they had not experienced any side effects to date. Methotrexate was perceived as a toxic and "heavy" medication. Biologics were described by patients as "life-changing" and superior to conventional DMARDs. Patients identified their relationship with their rheumatologist as being pivotal in their experience of their condition and medication management. Diet, exercise and stress were perceived to play a critical role in disease causation, flares and treatment.

Several minor themes were identified. Developing habitual patterned behaviour was a challenge for some participants. Affordability was an issue despite biologics being heavily subsidised. Depression, social situation and needle phobia were potential barriers to adherence. Preference for alternative therapy, distrust of "synthetic medications" and an awareness of the high cost of biologics affected decision making for some patients.

Conclusions: This study examined the medication adherence of a group of patients with rheumatic diseases who are very closely managed in a dedicated biologics clinic. Even in this group of patients, factors which contribute to medication non-adherence were readily identified. Several of these themes suggest that enhancing patient education may improve adherence in this group.
REFERENCES:

1) Pasma A, et al. Semin Arthritis Rheum2013;43:18-28.

2) Harrold LR, et al. Seminars in arthritis and rheumatism 2009;38:396-402.

3) Copher R, et al. Current medical research and opinion 2010;26:777-785.

4) Haynes RB, et al. The Cochrane Library 2008.

Disclosure of Interest: None declared

DOI: 10.1136/annrheumdis-2018-eular.5089

\section{FRI0636 \\ THE VALUE OF PERSISTENCE IN TREATMENT WITH SUBCUTANEOUS TNF-ALPHA INHIBITORS FOR ANKYLOSING SPONDYLITIS}

M. Ivergård ${ }^{1}$, J. Dalén ${ }^{1}$, A. Svedbom ${ }^{1}$, C. M. Black ${ }^{2}$, R. H. Borse ${ }^{2}$, S. Kachroo². ${ }^{1}$ Mapi, Stockholm, Sweden, ${ }^{2}$ Center for Observational and Real-World Evidence (CORE), Merck \& Co., Inc., Kenilworth, NJ, United States

Background: Subcutaneous Tumor Necrosis Factor-alpha inhibitors (SC-TNFi) with higher persistence are often perceived as being more costly compared with SC-TNFis with lower persistence based merely on the resulting higher drug acquisition cost. Thus, failing to consider possible health care cost offsets, productivity gains and increased quality of life.

Objectives: The objective of this study was to assess the value of higher treatment persistence by evaluating cost-effectiveness of SC-TNFis for Ankylosing Spondylitis (AS), with higher persistence compared with lower persistence from a payer and societal perspective.

Methods: A Markov cohort model, following the framework of the NICE commissioned York model in $\mathrm{AS}^{1}$, was developed. In the model, patients achieving BASDAI50 response at 12 weeks transition to treatment maintenance and nonresponders to conventional care. In each cycle, patients are at risk of death Patients discontinuing treatment after the treatment response period rebounds in BASDAI and BASFI by what was gained at response. Inputs were sourced from the York model where available and costs were updated to 2016/17 prices. The societal perspective included indirect costs from productivity losses (i.e. absenteeism, presenteeism, and early retirement) $)^{2}$. Two treatment strategies are investigated; SC-TNFis with constant annual withdrawal rates of $10 \%$ and $20 \%$. Apart from discontinuation rates, treatment inputs are the same for the two strategies. Results: Better persistence increases the treatment cost, but this is partly offset by savings in disease related costs and from a societal perspective it is cost-saving (figure 1). In addition, the improvement in the health of persistent patients is noticeable as a gain in quality adjusted life years (QALYs). The ICERs of the $10 \%$ and $20 \%$ withdrawal rate treatment strategies versus conventional care (CC) are $£ 18,323$ and $£ 20,063$, respectively (table 1). Given a WTP of $£ 20.000$ the strategy with better persistence compared to the strategy with worse persistence is clearly cost-effective $($ ICER $=£ 16,112)$ and dominates when a societal perspective is taken.

Table 1 Cost-effectiveness analysis of SC-TNFis

\begin{tabular}{|c|c|c|c|c|c|}
\hline & $\begin{array}{l}\text { Total } \\
\text { costs, } £\end{array}$ & $\begin{array}{l}\text { Total } \\
\text { QALYs }\end{array}$ & $\begin{array}{l}\text { Incremental } \\
\text { costs, } 乏\end{array}$ & $\begin{array}{l}\text { Incremental } \\
\text { QALYs }\end{array}$ & $\begin{array}{l}\text { Incremental cost } \\
\text { per QALY, } \Sigma\end{array}$ \\
\hline $\begin{array}{l}\text { Payer persf } \\
\text { SC-TNFis } \\
\text { vs. CC }\end{array}$ & tive & & & & \\
\hline $\mathrm{CC}$ & 128,016 & 9.71 & - & - & - \\
\hline $\begin{array}{l}10 \% \\
\text { withdrawal } \\
\text { rate }\end{array}$ & 146,146 & 10.70 & 18,130 & 0.99 & 18,323 \\
\hline $\begin{array}{l}20 \% \\
\text { withdrawal } \\
\text { rate }\end{array}$ & 139,379 & 10.28 & 11,363 & 0.57 & 20,063 \\
\hline $\begin{array}{l}\text { Between } \\
\text { SC-TNFis }\end{array}$ & - & - & 6,767 & 0.42 & 16,112 \\
\hline $\begin{array}{l}\text { Societal pe } \\
\text { SC-TNFis } \\
\text { vs. CC }\end{array}$ & ective & & & & \\
\hline $\mathrm{CC}$ & 326,454 & 9.71 & - & - & - \\
\hline $\begin{array}{l}10 \% \\
\text { withdrawal } \\
\text { rate }\end{array}$ & 322,537 & 10.70 & $-3,917$ & 0.99 & Dominates \\
\hline $\begin{array}{l}20 \% \\
\text { withdrawal } \\
\text { rate }\end{array}$ & 325,270 & 10.28 & $-1,184$ & 0.57 & Dominates \\
\hline $\begin{array}{l}\text { Between } \\
\text { SC-TNFis }\end{array}$ & - & - & $-2,733$ & 0.42 & $10 \%$ dominates \\
\hline
\end{tabular}




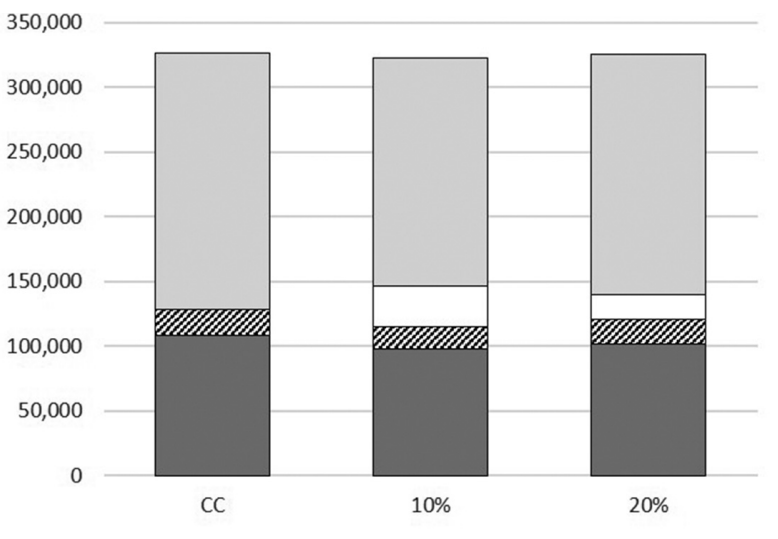

$\square$ Disease related costs $\square$ Cost of CC $\square$ Cost of SC-TNFis $\square$ Indirect costs

Conclusions: Persistence appears to be a driver of cost-effectiveness of SCTNFi treatment in patients with AS, especially when a societal perspective is taken. Therefore, prescribing the SC-TNFi with the best persistence may be a cost-effective strategy.

\section{REFERENCES:}

1. Corbett $M$, et al. Tumour necrosis factor-alpha inhibitors for ankylosing spondylitis and non-radiographic axial spondyloarthritis: a systematic review and economic evaluation. Health Technology Assessment (Winchester, England) 2016;20(9):1-334, v-vi.

2. Raffia R, et al. Healthcare costs and productivity losses directly attributable to ankylosing spondylitis. Clinical and Experimental Rheumatology 2012;30:246-253.

Disclosure of Interest: M. Ivergård Employee of: Mapi, J. Dalén Employee of: Mapi, A. Svedbom Employee of: Mapi, C. Black Shareholder of: Merck \& Co., Inc., Employee of: Merck \& Co., Inc., R. Borse Shareholder of: Merck \& Co., Inc., Employee of: Merck \& Co., Inc., S. Kachroo Shareholder of: Merck \& Co., Inc., Employee of: Merck \& Co., Inc.

DOI: 10.1136/annrheumdis-2018-eular.2100

\section{FRI0637 BARRIERS TO REMAIN IN WORK: RESULTS FROM THE NATIONAL RHEUMATOID ARTHRITIS SOCIETY SURVEY (NRAS)}

S. Verstappen ${ }^{1,2}$, L. Lunt ${ }^{1}$, A. Bosworth ${ }^{3}$, M. Bezzant ${ }^{3}$, K. Walker-Bone ${ }^{2} .{ }^{1}$ Centre for Musculoskeletal Research, the University of Manchester, Manchester, ${ }^{2}$ ARUK/ MRC Centre for Musculoskeletal Health and Work, Southampton, ${ }^{3}$ NRAS, Maidenhead, United Kingdom

Background: Problems at work and work loss are still major socio-economic consequences for patients with Rheumatoid Arthritis (RA), employers and the society. Currently, there is a lack of understanding what the main barriers and facilitators are to remain in paid work. For patients and employers identifying these barriers and facilitators will enable them to make the right adjustments at a personal level. For policy makers these factors can determine future policies, aiming to reduce the overall socio-economic burden of RA.

Objectives: i) To understand reasons for work loss in people with RA; and ii) to compare problems at work in employed RA patients and those who had to stop working due to RA.

Methods: An online survey about employment was sent to UK NRAS members and distributed to non-members via social media including questions about problems at work in those employed or problems related to work in those who had to stop working or retire early due to RA. Rates of problems related to work were compared using Chi2 tests.

Results: 891 patients who completed the survey were in paid employment and 189 had stopped working due to RA or retired early due to their RA. Median [IQR] symptom duration was 12.5 [7.5-23.2] years and the majority were women (91\%). Main reasons for leaving work included (patients could tick all that applied): unable to carry out duties $(73 \%)$; time off sick $(46 \%)$; fatigue $(74 \%)$; problems with colleagues (12\%); need for specific adaptations (11\%); unable to travel to work $(13 \%)$; lack of family support (3\%); lack of support from employer (33\%); and side effects of medication (24\%). The majority of patients left their job $>5$ years earlier than they had expected (72\%) and 62/172 (36\%) mentioned that their employer had not been helpful in assisting them to stay in work. For those in employment, the main challenges to remain in work were: demanding role; RA symptoms; no reasonable adjustments; commuting to work; and lack of understanding. Compared to patients in employment at time of survey, those who had to stop work due to their arthritis, reported having significantly serious problems regarding commuting to work, lack of understanding employers/colleagues, time off due to flare or medical appointments, health and safety and reluctance to make adjustments in their last job (table 1). Lack of family support was not significantly significant.

\begin{tabular}{|c|c|c|c|c|c|c|c|}
\hline & \multicolumn{2}{|c|}{\begin{tabular}{|c|} 
not at all serious/ not very \\
serious
\end{tabular}} & \multicolumn{2}{|c|}{$\begin{array}{l}\text { neither serious nor non- } \\
\text { serious }\end{array}$} & \multicolumn{2}{|c|}{ serious / very serious } & \multirow[t]{2}{*}{$P$} \\
\hline & Employed & $\begin{array}{c}\text { Stopped } \\
\text { working due } \\
\text { to arthritis }\end{array}$ & Employed & \begin{tabular}{|c} 
Stopped \\
working due \\
to arthritis
\end{tabular} & Employed & $\begin{array}{c}\text { Stopped } \\
\text { working due } \\
\text { to arthritis }\end{array}$ & \\
\hline Getting to and from work & $326 / 609(53 \%)$ & $58 / 166(35 \%)$ & $136 / 609(22 \%)$ & $36 / 166(22 \%)$ & $\mid 147 / 609(24 \%)$ & $72 / 166(43 \%)$ & $<0.001$ \\
\hline $\begin{array}{l}\text { Lack of understanding } \\
\text { from colleagues }\end{array}$ & $300 / 603(50 \%)$ & $38 / 159(24 \%)$ & $129 / 603(21 \%)$ & $42 / 159(26 \%)$ & $174 / 603(29 \%$ & $79 / 129(50 \%)$ & $<0.001$ \\
\hline Health and Safety issues & $303 / 594(51 \%)$ & $56 / 161(35 \%)$ & $170 / 594(29 \%)$ & $41 / 161(25 \%)$ & $121 / 594(20 \%)$ & 64/161(40\%) & $<0.001$ \\
\hline $\begin{array}{l}\begin{array}{l}\text { Time of medical } \\
\text { appointments }\end{array} \\
\end{array}$ & $362 / 624(58 \%)$ & $62 / 167(37 \%)$ & $108 / 624(17 \%)$ & $39 / 167(23 \%)$ & $154 / 624(25 \%)$ & $66 / 167(40 \%)$ & $<0.001$ \\
\hline Lack of family support & $378 / 617(61 \%)$ & \begin{tabular}{|l|l|l|}
$93 / 147$ \\
$(63 \%)$
\end{tabular} & $111 / 617(18 \%)$ & $29 / 147(20 \%)$ & $\mid 128 / 617(21 \%)$ & $25 / 147(17 \%)$ & 0.577 \\
\hline $\begin{array}{l}\text { Time off when having a } \\
\text { flare or unwell }\end{array}$ & $245 / 603(41 \%)$ & $29 / 165$ (18\%) & $|107 / 603(18 \%)|$ & $17 / 165(10 \%)$ & $251 / 603(42 \%)$ & $119 / 165$ (72\%) & $\mid<0.001$ \\
\hline $\begin{array}{l}\text { Employer reluctant to } \\
\text { make adjustments }\end{array}$ & $282 / 538(52 \%)$ & $38 / 151$ (25\%) & $134 / 538(25 \%)$ & $35 / 151(23 \%)$ & $\mid 122 / 538(23 \% 6)$ & $78 / 151(52 \%)$ & $<0.001$ \\
\hline $\begin{array}{l}\text { Lack of understanding } \\
\text { employer }\end{array}$ & $281 / 573(49 \%)$ & $36 / 156(23 \%)$ & $118 / 573(21 \%)$ & $27 / 156(17 \%)$ & $174 / 573(30 \%)$ & 93/156 (60\%) & $<0.001$ \\
\hline
\end{tabular}

Conclusions: Barriers to remain in work with RA are multi-factorial and related to the disease, nature of the work and understanding from employers and colleagues. Increasing understanding about RA amongst employers and colleagues in addition to often simple work adjustments, such as adaptations in the workplace and the opportunity to work more flexible, can prevent problems at work and work loss in the long-term and reduce the socio-economic burden.

Disclosure of Interest: None declared

DOI: 10.1136/annrheumdis-2018-eular.5393

\section{FRI0638 \\ A NOVEL GROUP CLINIC MODEL FOR NEW PATIENTS ENHANCES PATIENT ACTIVATION}

T. Jones $^{1,2}$, A. Morbi ${ }^{3}$, M. Grove ${ }^{1}$, F. Birrell ${ }^{1,4} .{ }^{1}$ Northumbria Healthcare NHS Foundation Trust, Newcastle upon Tyne, ${ }^{2}$ University of Sunderland, Sunderland, ${ }^{3}$ Imperial College, London, ${ }^{4}$ Newcastle University, Newcastle upon Tyne, United Kingdom

Background: Group clinics are a widely used, key alternative care model in USA (as shared medical appointments and other labels), especially in centres of excellence like the Cleveland Clinic. They are increasingly seen as 'a transformative innovation'1 and recognised as an effective solution to the universal healthcare challenges: increasing demand and limited resource ${ }^{2}$. We have extensive experience of follow up group clinics for inflammatory arthritis patients since 2008 with a co-designed model integrating patient and team views ${ }^{3}$. Qualitative research showed robust themes associated with successful delivery: Efficiency, Empathy, Education, Engagement and Empowerment. 'Patient activation' describes the knowledge, skills and confidence a person has in managing their own healthcare, but there is no published data in group clinics. A group model has also never been used for seeing new patients in secondary care, so this is an original application of an established care model.

Objectives: To show feasibility for new patients seen in a group setting and assess patient experience, including activation.

Methods: A mixed methods pilot study. New patients awaiting Rheumatology appointments were invited to pilots at one of two hospitals: 1) with experience of group clinics 2) without. Patients agreeing to attend knew this was a new application of an established innovation with an option to stay for a focus group or be interviewed by telephone afterwards. Sessions were videoed for educational purposes and qualitative interviews were conducted under existing research approvals with relevant consents for both. Numerical data included Patient Activation Measure before/after the two-hour clinic, EQ-5D and a standard feedback tool. Qualitative data was analysed using nVivo and compared to previously identified themes.

Results: 19 patients were seen in two two-hour clinics (mean 13 mins/patient vs. 30 mins/patient usual care), including complex patients with multiple diagnoses. 69 patients were phoned, of whom 16 did not answer, 20 declined, 6 failed to attend, 3 declined to see a Rheumatologist at all, 2 were deemed not suitable and 3 already had an appointment. Feedback was very positive: median 10 (IQR 810) across all domains, so was consistent with usual clinics and follow up group clinics. Free text positive comments far outweighing the negative. EQ-5D showed a highly impacted group (mean global health index 54 vs. UK age norm 77) Patient Activation Measure showed significant improvement over each two-hour 